\title{
Ochrobactrum pituitosum sp. nov., isolated from an industrial environment
}

\author{
Birgit Huber, ${ }^{1}$ Holger C. Scholz, ${ }^{2}$ Peter Kämpfer, ${ }^{3}$ Enevold Falsen, ${ }^{4}$ \\ Stefan Langer ${ }^{1}$ and Hans-Jürgen Busse ${ }^{1}$
}

Correspondence

Hans-Jürgen Busse

hans-juergen.busse@

vetmeduni.ac.at

\author{
${ }^{1}$ Institut für Bakteriologie, Mykologie und Hygiene, Veterinärmedizinische Universität, A-1210 Wien, \\ Austria \\ ${ }^{2}$ Bundeswehr Institute of Microbiology and Toxicology, D-80937 Munich, Germany \\ ${ }^{3}$ Institut für Angewandte Mikrobiologie, Justus-Liebig-Universität Giessen, D-35392 Giessen, \\ Germany \\ ${ }^{4}$ CCUG - Culture Collection University of Göteborg, S-413 46 Göteborg, Sweden
}

Strain CCUG 50899, a Gram-negative, rod-shaped, non-spore-forming, motile bacterium isolated from industrial environment in Sweden and tentatively assigned to the species Ochrobactrum anthropi, was studied in order to clarify its taxonomic status. 16S rRNA gene sequence similarities placed the strain in the genus Ochrobactrum, sharing highest similarity with the type strains of Ochrobactrum rhizosphaerae (99.3\%), Ochrobactrum thiophenivorans (98.7\%), Ochrobactrum pseudogrignonense (98.6\%) and Ochrobactrum grignonense (98.5\%). The fatty acid profile of [O. anthropi] CCUG 50899 (major fatty acids $\mathrm{C}_{18: 1} \omega 7 \mathrm{c}$ and $\mathrm{C}_{19: 0}$ cyclo $\omega 8 \mathrm{c}$ and presence of $\mathrm{C}_{18: 1} 2-\mathrm{OH}$ ), the polar lipid profile (diphosphatidylglycerol, phosphatidylglycerol, phosphatidylmonomethylethanolamine, phosphatidylethanolamine, two unknown aminolipids and an unknown phospholipid), the presence of the quinone system ubiquinone $\mathrm{Q}-10$ and a polyamine pattern with the major compounds putrescine and spermidine and moderate amounts of sym-homospermidine supported its affiliation to the genus Ochrobactrum. DNA-DNA reassociation experiments with the type strains of its closest relatives O. rhizosphaerae, O. pseudogrignonense, O. thiophenivorans and O. grignonense demonstrated that [O. anthropi] CCUG 50899 should be placed in a novel species, which is distinguishable from related species by a set of biochemical traits. Based on these data, reclassification of [O. anthropi] CCUG 50899 as the type strain of a novel species appears to be justified. Hence, we describe a novel species to accommodate this strain, for which we propose the name Ochrobactrum pituitosum sp. nov. The type strain is CCUG $50899^{\top}\left(=\mathrm{DSM} 22207^{\top}\right.$ ).
The genus Ochrobactrum is affiliated with the family Brucellaceae (Garrity et al., 2005). 16S rRNA gene and recA sequence-based phylogenies both suggest that the genera Brucella and Ochrobactrum could be unified in a single genus (Kämpfer et al., 2008; Scholz et al., 2006, 2008). At the time of writing, the genus comprises 13 species: Ochrobactrum anthropi (Holmes et al., 1988), O. intermedium (Velasco et al., 1998), O. tritici and O. grignonense (Lebuhn et al., 2000), O. gallinifaecis (Kämpfer et al., 2003), O. oryzae (Tripathi et al., 2006), O. lupini (Trujillo et al.,

Abbreviations: pNA, $p$-nitroanilide; pNP, $p$-nitrophenyl.

The GenBank/EMBL/DDBJ accession numbers for the partial groEL and gyrB sequences of $\mathrm{O}$. rhizosphaerae PR $17^{\top}$, Ochrobactrum sp. CCUG 50899, O. grignonense OgA9a', O. pseudogrignonense CCUG $30717^{\top}$ and $O$. thiophenivorans DSM $7216^{\top}$ are respectively FM863819-FM863823 (groEL) and FM863818 and FM863814FM863817 (gyrB).
2005), O. pseudintermedium (Teyssier et al., 2007), O. cytisi (Zurdo-Piñeiro et al., 2007), O. haematophilum and O. pseudogrignonense (Kämpfer et al., 2007), O. rhizosphaerae and O. thiophenivorans (Kämpfer et al., 2008). In a comprehensive study, Scholz et al. (2008) examined the phylogenetic relationships of numerous Ochrobactrum and Brucella strains including strain CCUG 50899, reported as a strain of O. anthropi according to the CCUG catalogue but which was shown to be phylogenetically distant from the type strain of $O$. anthropi on the basis of both 16S rRNA gene and recA phylogeny. In comparison to the majority of Ochrobactrum strains, [O. anthropi] CCUG 50899 shows an insertion of $47 \mathrm{nt}$ (positions 124-170) in the 16S rRNA gene sequence (GenBank accession no. AM490609) which so far has only been reported for some strains of $O$. intermedium (Teyssier et al., 2003; Scholz et al., 2008). Corrected for the insertion sequence, [O. anthropi] CCUG 
50899 shares highest 16S rRNA gene sequence similarity with O. rhizosphaerae $\mathrm{PR}^{2} 7^{\mathrm{T}}(99.3 \%)$, O. thiophenivorans DSM $7216^{\mathrm{T}}(98.7 \%)$, O. pseudogrignonense CCUG $30717^{\mathrm{T}}$ $(98.6 \%)$ and O. grignonense $\mathrm{OgA9}^{\mathrm{T}}(98.5 \%)$. Other Ochrobactrum species show lower similarity values. Based on partial recA sequence similarities, $O$. grignonense $\mathrm{OgA9a}^{\mathrm{T}}(93.3 \%)$ and O. rhizosphaerae $\mathrm{PR} 17^{\mathrm{T}}(91.4 \%)$ are the closest relatives of [O. anthropi] CCUG 50899 (GenBank accession no. AM422871), with other members of Ochrobactrum sharing only $83.5-88.3 \%$ similarity in the corresponding partial gene sequences. However, these similarity values demonstrate unambiguously the affiliation of [O. anthropi] CCUG 50899 to the genus Ochrobactrum. Here, we report the classification of [O. anthropi] CCUG 50899, applying biochemical, physiological, chemotaxonomic and genetic characterization and comparison to phylogenetic relatives identified recently based on $16 \mathrm{~S}$ rRNA gene and recA phylogenies (Scholz et al., 2006, 2008).

Recalculation of its $16 \mathrm{~S}$ rRNA gene sequence-based phylogenetic position placed [O. anthropi] CCUG 50899 on a separate branch within Ochrobactrum consisting of the type strains of $O$. grignonense, $O$. pseudogrignonense, $O$. thiophenivorans and the closest related species O. rhizosphaerae with high bootstrap support (Fig. 1), which is in agreement with the relationship indicated by $16 \mathrm{~S}$ rRNA gene sequence similarities.

Since $16 \mathrm{~S}$ rRNA gene and recA sequence analyses had identified different Ochrobactrum species as the closest relatives, partial gyrB (1032 nt) and groEL (1169 nt) sequences of [O. anthropi] CCUG 50899 were analysed and compared to the corresponding sequences of selected reference strains, including $O$. anthropi LMG $3331^{\mathrm{T}}, O$. grignonense $\mathrm{OgA} 9 \mathrm{~A}^{\mathrm{T}}$, O. rhizosphaerae $\mathrm{PR} 17^{\mathrm{T}}$, O. thiophenivorans DSM $7216^{\mathrm{T}}$, O. pseudogrignonense CCUG $30717^{\mathrm{T}}$ and O. intermedium LMG $3301^{\mathrm{T}}$. DNA was released by subjecting a cell suspension in sterile water to three cycles of freezing in liquid nitrogen and thawing at $60{ }^{\circ} \mathrm{C}$. Released DNA in the supernatant obtained after a short centrifugation was used as the template in PCRs. Partial gyrB and groEL sequences were amplified with the primer pairs GyrB_f [5'-GATGATGATCTTGTG(AG)TA(AGC)CGCAG-3'] and GyrB_r (5'-CGAGGTCATCATGACCCAGCTTC- $\left.3^{\prime}\right)$ and GroEL_f (5'-CGGCGAAGACCTGCTGATC- $\left.3^{\prime}\right)$ and GroEL_r (5'-GCAACGATACCTTCTTCAACCG-3'), respectively. The $50 \mu \mathrm{l}$ assay contained primers (0.5 pmol $\left.\mu \mathrm{l}^{-1}\right), \mathrm{MgCl}_{2}(3 \mathrm{mM})$, dNTPs $(0.2 \mathrm{mM}$ each), $10 \mu \mathrm{l} 5 \times$ GoTaq Flexi buffer and GoTaq DNA Polymerase enzyme (1.25 U; Promega), 1-2 $\mu$ l DNA preparation and sterile water. For both primer pairs, PCR amplification was performed using the following conditions: $5 \mathrm{~min}$ initial denaturation at $95{ }^{\circ} \mathrm{C}$ followed by 35 cycles of denaturation for $1 \mathrm{~min}$ at $95^{\circ} \mathrm{C}$, annealing for $1 \mathrm{~min}$ at $64{ }^{\circ} \mathrm{C}$ and extension for $90 \mathrm{~s}$ at $72{ }^{\circ} \mathrm{C}$ with a final extension for $5 \mathrm{~min}$ at $72{ }^{\circ} \mathrm{C}$. PCR products were excised from a $1.5 \%$ agarose gel and then purified with the QIAquick gel extraction kit (Qiagen). Products were sequenced at VBC Genomics (Vienna, Austria). Primers GyrB_r, GyrB_int_544_r (5' GACGCTGACCGGCGATGACTG-3'), GroEL_f and GroEL_r were used as sequencing primers. Multiple sequence alignment was made with the CLUSTAL_X software, version 1.81 (Thompson et al., 1997), and a similarity matrix was calculated with the software BioEdit (Hall, 1999).

For the partial groEL gene sequences, similarities between the reference strains were in the range $91.3-96.0 \%$ (Table 1). For the partial gyrB sequences, similarity values between the reference strains were significantly lower, ranging from 83.9 to $91.5 \%$. In both partial gene sequences, [O. anthropi] CCUG 50899 exhibited highest similarity with $O$. grignonense $O g \mathrm{OA}^{\mathrm{T}}$ ( $97.9 \%$ for groEL, $95.0 \%$ for $g y r B)$, suggesting this species as the closest relative and thus confirming the results from $r e c A$ analyses (Scholz et al., 2008). Similarity values with the reference

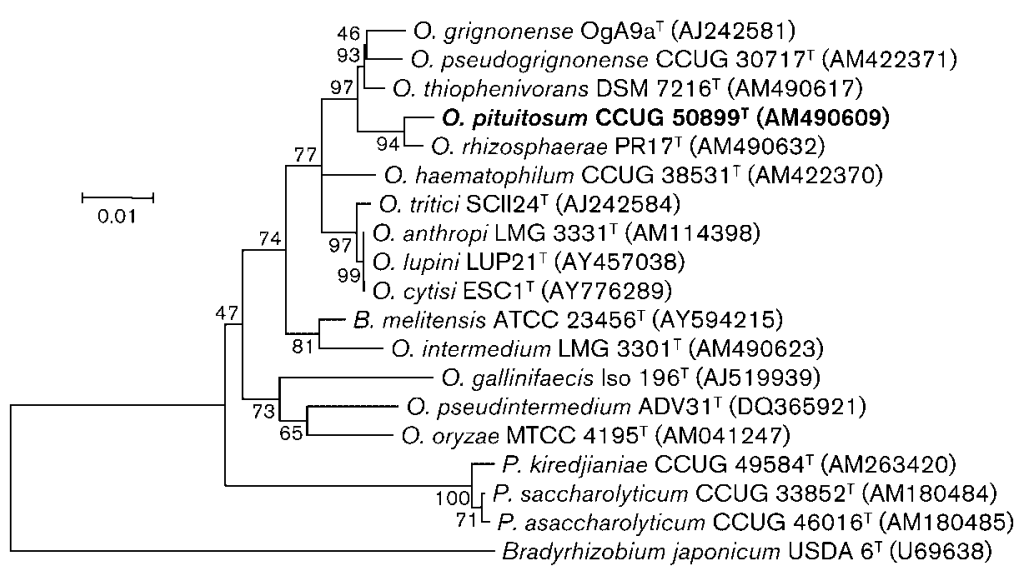

Fig. 1. Phylogenetic tree based on $16 \mathrm{~S}$ rRNA gene sequences (1355-1394 bp) available from the EMBL database constructed after multiple alignment of data by CLUSTAL_X (Thompson et al., 1997). Distances (distance options according to the maximum composite likelihood model) were calculated and clustering with the neighbour-joining method was performed using the software package MEGA version 4.0 (Tamura et al., 2007). Bootstrap values based on 2000 replications are listed as percentages at branching points (the bootstrap consensus tree is shown). Bar, 0.01 substitutions per nucleotide position. O., Ochrobactrum; B., Brucella; P., Pseudochrobactrum. The sequence of Bradyrhizobium japonicum USDA $6^{\top}$ was used as an outgroup. 
Table 1. Similarities of partial groEL and $g y r B$ sequences

groEL similarities are given as percentages above the diagonal, with percentage gyrB similarities below the diagonal. Sequences were aligned using CLUSTAL_X (Thompson et al., 1997) and sequence similarities were determined using BioEdit (Hall, 1999). Values for [O. anthropi] CCUG 50899 are highlighted in bold.

\begin{tabular}{|c|c|c|c|c|c|c|c|}
\hline Strain & 1 & 2 & 3 & 4 & 5 & 6 & 7 \\
\hline 2. O. grignonense $\mathrm{OgA} 9 \mathrm{~A}^{\mathrm{T}}$ & 85.8 & - & 97.9 & 95.2 & 94.9 & 92.4 & 92.8 \\
\hline 4. O. rhizosphaerae $\mathrm{PR} 17^{\mathrm{T}}$ & 83.9 & 87.1 & 87.5 & - & 95.8 & 92.8 & 92.1 \\
\hline 5. O. thiophenivorans DSM $7216^{\mathrm{T}}$ & 84.6 & 85.3 & 83.2 & 85.1 & - & 92.6 & 91.3 \\
\hline 6. O. pseudogrignonense CCUG $30717^{\mathrm{T}}$ & 87.1 & 88.9 & 89.1 & 85.6 & 85.4 & - & 92.8 \\
\hline
\end{tabular}

strains were in the range 92.4-95.6\% (groEL) and 83.2$89.1 \%(\operatorname{gyr} B)$, respectively. Similarity of $92.4 \%$ (groEL) and $86.0 \%($ gyrB) between [O. anthropi] CCUG 50899 and O. anthropi LMG $3331^{\mathrm{T}}$ does not suggest a relationship at the species level.

In order to clarify whether [O. anthropi] CCUG 50899 should be considered a member of a separate species, DNA-DNA hybridizations were carried out with DNAs of the nearest relatives $O$. grignonense $O g A 9 \mathrm{a}^{\mathrm{T}}, O$. thiophenivorans DSM $7216^{\mathrm{T}}$, O. pseudogrignonense CCUG $30717^{\mathrm{T}}$ and O. rhizosphaerae $\mathrm{PR}^{\mathrm{T}}{ }^{\mathrm{T}}$. High-molecular-mass DNA was extracted and purified according to Pitcher et al. (1989). DNA concentrations were estimated chemically according to Richards (1974). DNA-DNA hybridizations were performed according to Ziemke et al. (1998) except that, for nick translation, $2 \mu \mathrm{g}$ DNA was labelled during a 90 min incubation at $15{ }^{\circ} \mathrm{C}$. In the hybridization experiments, DNA of [O. anthropi] CCUG 50899 exhibited $55 \%$ (reciprocal 56\%) reassociation with $O$. grignonense OgA9a ${ }^{\mathrm{T}}, 47 \%$ (reciprocal $37 \%$ ) reassociation with $O$. thiophenivorans DSM $7216^{\mathrm{T}}, 62 \%$ (reciprocal $35 \%$ ) with O. pseudogrignonense CCUG $30717^{\mathrm{T}}$ and $43 \%$ (reciprocal $46 \%$ ) reassociation with $O$. rhizosphaerae $\mathrm{PR} 17^{\mathrm{T}}$. These data demonstrate that [O. anthropi] CCUG 50899 represents a novel species of the genus Ochrobactrum.

For phenotypic characterization, [O. anthropi] CCUG 50899 was subjected to the set of methods already employed for classification of O. haematophilum, $O$. pseudogrignonense, O. rhizosphaerae and O. thiophenivorans (Kämpfer et al., 2007, 2008).

Polar lipids and quinones were extracted from biomass grown in PYE medium ( $0.3 \%$ peptone from casein, $0.3 \%$ yeast extract, $\mathrm{pH}$ 7.2) and analysed as described previously (Tindall, 1990a, b; Altenburger et al., 1996; Stolz et al., 2007). Polyamines were extracted and analysed as described by Busse \& Auling (1988) and Stolz et al. (2007). Analysis of quinones indicated that [O. anthropi] CCUG 50899 contains a quinone system with ubiquinone Q-10 (99\%) predominating and minor amounts of ubiquinone Q-9 (1\%). The polar lipid profile of [O. anthropi] CCUG 50899 exhibited all the major compounds reported for other Ochrobactrum species, including the characteristic aminolipid AL2 (Kämpfer et al., 2003, 2007, 2008). Differences in the presence of minor, quite hydrophilic components were detected (Fig. 2), but we do not want to give too much emphasis here to this observation because, so far, its significance has not been demonstrated by results from other strains of the same species. The polyamine pattern contained the major compounds putrescine and spermidine $[34.2$ and $27.6 \mu \mathrm{mol}$ (g dry weight $)^{-1}$, respectively], moderate amounts of sym-homospermidine $[4.6 \mu \mathrm{mol}$ (g dry weight $)^{-1}$ ] and small amounts of spermine and 1,3diaminopropane $[0.9 \text { and } 0.4 \mu \mathrm{mol} \text { (g dry weight })^{-1}$, respectively], which is characteristic of Ochrobactrum

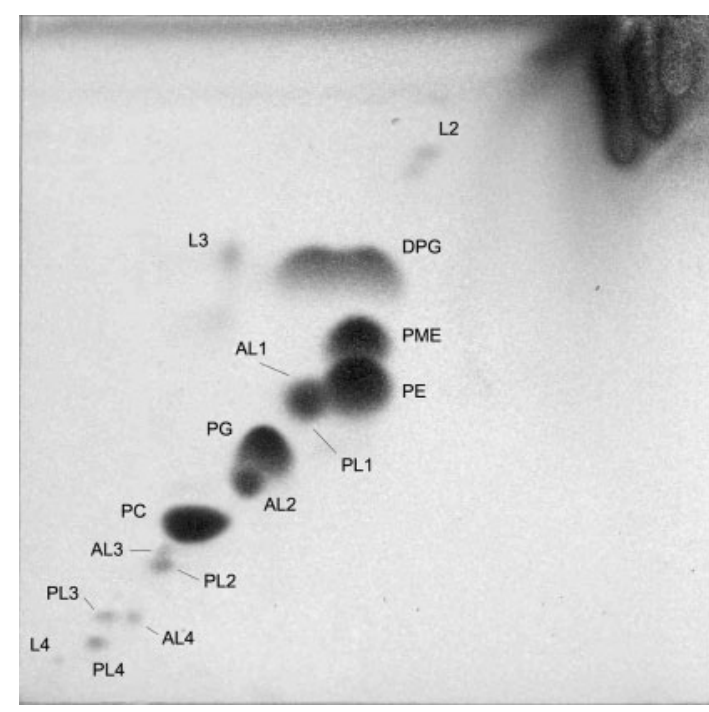

Fig. 2. Total polar lipid profile of [O. anthropi] CCUG 50899 after two-dimensional TLC and detection with molybdatophosphoric acid. DPG, Diphosphatidylglycerol; PC, phosphatidylcholine; PE, phosphatidylethanolamine; PG, phosphatidylglycerol; $\mathrm{PME}$, phosphatidylmonomethylethanolamine; $\mathrm{AL} 1-4$, unknown aminolipids; L2-4, unknown polar lipids; PL1-4, unknown phospholipids. 
species (Kämpfer et al., 2007, 2008). Fatty acids were extracted and analysed according to the instructions of the Microbial Identification System (MIDI Inc.) as described before (Kämpfer \& Kroppenstedt, 1996). The fatty acid profile of [O. anthropi] CCUG 50899 exhibited the characteristics also reported for other species of the genus (Table 2). The fatty acids $\mathrm{C}_{18: 1} \omega 7 c$ and $\mathrm{C}_{19: 0}$ cyclo $\omega 8 c$ were predominant and the hydroxy acid $\mathrm{C}_{18: 1} 2-\mathrm{OH}$ was detected. Examination of the fatty acid profile from cells grown for only $24 \mathrm{~h}$ (all other analyses were carried out from cells grown for $48 \mathrm{~h}$ ) showed a significantly increased amount of $\mathrm{C}_{18: 1} \omega 7 c$ and decreased amount of $\mathrm{C}_{19: 0}$ cyclo $\omega 8 c$, but the sum of the two amounts was almost the same as in cells grown for $48 \mathrm{~h}$. This observation demonstrates that, for comparison of fatty acid profiles of Ochrobactrum strains, only the sum of the amounts of $\mathrm{C}_{18: 1} \omega 7 c$ and $\mathrm{C}_{19: 0}$

Table 2. Fatty acid compositions of [O. anthropi] CCUG 50899 and the type strains of closely related species

Strains: 1, [O. anthropi] CCUG 50899; 2, O. rhizosphaerae PR $17^{\mathrm{T}}$ (data from Kämpfer et al., 2008); 3, O. grignonense DSM $13338^{\mathrm{T}}$ (Kämpfer et al., 2007); 4, O. pseudogrignonense CCUG $30717^{\mathrm{T}}$ (Kämpfer et al., 2007); 5, O. thiophenivorans DSM $7216^{\mathrm{T}}$ (Kämpfer et al., 2008). All strains were grown on TSA at $28{ }^{\circ} \mathrm{C}$ for $48 \mathrm{~h}$ prior to fatty acid analysis; [O. anthropi] CCUG 50899 was also analysed for fatty acids after growth under the same conditions for $24 \mathrm{~h}$ (in parentheses). For unsaturated fatty acids, the position of the double bond is located by counting from the methyl $(\omega)$ end of the carbon chain; cis isomers are indicated by the suffix $c$.

\begin{tabular}{|lccccc|}
\hline Fatty acid & $\mathbf{1}$ & $\mathbf{2}$ & $\mathbf{3}$ & $\mathbf{4}$ & $\mathbf{5}$ \\
\hline Saturated fatty acids & & & & & \\
$\mathrm{C}_{16: 0}$ & $4.9(2.7)$ & 8.3 & 2.9 & 9.7 & 7.3 \\
$\mathrm{C}_{17: 0}$ & $2.3(1.6)$ & 2.8 & 1.7 & 1.6 & 1.4 \\
$\mathrm{C}_{18: 0}$ & $8.6(7.7)$ & 7.6 & 7.2 & 4.9 & 2.9 \\
Unsaturated fatty acids & & & & & \\
$\mathrm{C}_{13: 1}$ at $12-13$ & - & - & 0.7 & - & - \\
$\mathrm{C}_{17: 1} \omega 6 c$ & - & - & 0.5 & - & - \\
$\mathrm{C}_{18: 1} \omega 7 c$ & $22.5(61.3)$ & 61.5 & 31.6 & 19.2 & 40.9 \\
$11-$ Methyl $\mathrm{C}_{18: 1} \omega 7 c$ & $0.9(-)$ & - & 1.0 & 1.7 & 1.5 \\
$\mathrm{C}_{20: 1} \omega 7 c$ & $0.4(0.7)$ & - & 0.8 & - & - \\
$\mathrm{C}_{20: 2} \omega 6,9 c$ & $0.6(-)$ & - & 0.8 & 0.9 & 1.8 \\
Hydroxy fatty acids & & & & & \\
$\mathrm{C}_{18: 1} 2-\mathrm{OH}$ & $0.6(2.0)$ & 4.7 & 0.5 & 1.8 & 1.5 \\
$\mathrm{C}_{18: 1} 3-\mathrm{OH}$ & $0.4(-)$ & - & 0.5 & 0.5 & - \\
Summed feature $3^{\star}$ & $1.2(1.5)$ & 4.6 & 1.0 & 1.4 & 5.8 \\
Cyclopropane acids & & & & & \\
$\mathrm{C}_{17: 0}$ cyclo & 1.0 & - & - & 1.0 & 2.1 \\
$\mathrm{C}_{19: 0}$ cyclo $\omega 8 c$ & $56.0(20.8)$ & 11.2 & 50.2 & 57.0 & 34.9 \\
Unknown $13.957 \dagger$ & 0.6 & - & 0.2 & 0.3 & - \\
Unknown $14.959 \dagger$ & $-(0.7)$ & - & 0.7 & - & - \\
& & & & & \\
\hline
\end{tabular}

* Summed feature 3 contained $\mathrm{C}_{15: 0}$ iso $2-\mathrm{OH}$ and/or $\mathrm{C}_{16: 1} \omega 7 \mathrm{c}$. Since no other iso-branched fatty acids were detected, it is most likely that summed feature 3 in fact represents only $\mathrm{C}_{16: 1} \omega 7 c$.

$\dagger$ Unknown fatty acids not identified by the MIDI system. Values are equivalent chain-lengths. cyclo $\omega 8 c$ should be considered. In contrast to O. rhizosphaerae $\mathrm{PR} 17^{\mathrm{T}}$ and $O$. thiophenivorans DSM $7216^{\mathrm{T}}$, small amounts of the hydroxy acid $\mathrm{C}_{18: 1} 3-\mathrm{OH}$ were also detected.

Tolerance towards $\mathrm{NaCl}$ was examined on PYE agar supplemented with $1,2,3,4,5,6,7$ and $10 \% \mathrm{NaCl}$ (w/v) and temperature tolerance was examined in an adjustable incubator. Other phenotypic characteristics were studied using the methods described by Kämpfer et al. (1991).

Physiological and biochemical traits are listed in Table 3 and the species description. Biochemical characterization of [O. anthropi] CCUG 50899 showed that this strain is distinguishable from the type strains of the closest related species including $O$. rhizosphaerae $\mathrm{PR} 17^{\mathrm{T}}$, O. grignonense DSM $13338^{\mathrm{T}}$, O. pseudogrignonense CCUG $30717^{\mathrm{T}}$ and $O$. thiophenivorans DSM $7216^{\mathrm{T}}$ as well as from $O$. anthropi CIP $14970^{\mathrm{T}}$ based on a set of traits. These data support our view that strain CCUG 50899 is affiliated neither with $O$. anthropi nor with any of the other related species.

Phylogenetically, [O. anthropi] CCUG 50899 is affiliated unambiguously with the genus Ochrobactrum, and its chemotaxonomic traits such as quinone system, polar lipid profile, fatty acids and polyamine pattern are in agreement with this classification. Results from DNA-DNA hybridizations demonstrate that Ochrobactrum sp. CCUG 50899 is a representative of a novel species that differs in several phenotypic traits from phylogenetically closely related species. Hence, we here describe a novel species to accommodate strain CCUG 50899, for which we propose the name Ochrobactrum pituitosum sp. nov.

\section{Description of Ochrobactrum pituitosum sp. nov.}

Ochrobactrum pituitosum (pi.tu.i.to'sum. L. neut. adj. pituitosum slimy, referring to the consistency of the colonies after extended incubation).

Cells stain Gram-negative and also show Gram-negative behaviour in the $\mathrm{KOH}$ and aminopeptidase tests. Aerobic. Highly motile in the early exponential growth phase but may become less motile or non-motile when approaching the stationary growth phase. Cells are non-spore-forming, pleomorphic rods (approx. 1.5-2.5 $\mu \mathrm{m}$ long). Good growth is observed on Columbia agar supplemented with sheep blood and on nutrient agar, TSA, PYE agar, R2A agar and MacConkey agar. Growth is observed on PYE agar supplemented with $6 \% \mathrm{NaCl}$ but not with $7 \% \mathrm{NaCl}(\mathrm{w} / \mathrm{v})$. Optimal growth occurs at $25-30{ }^{\circ} \mathrm{C}$; weak growth at 20 and $35{ }^{\circ} \mathrm{C}$. No growth occurs at $4{ }^{\circ} \mathrm{C}$ or at temperatures above $35{ }^{\circ} \mathrm{C}$ on PYE agar. Small, beige, translucent and shiny colonies up to $1 \mathrm{~mm}$ in diameter are formed within $24 \mathrm{~h}$ on PYE agar. After extended incubation, colonies become slimy. Oxidase- and catalase-positive. The quinone system consists of the predominant ubiquinone Q-10 and minor amounts of Q-9. The polyamine pattern consists of the major compounds spermidine and putrescine, moderate amounts of sym-homospermidine and minor amounts of 1,3-diaminopropane and spermine. Predominant polar 
Table 3. Physiological characteristics of [O. anthropi] CCUG 50899, O. anthropi CIP $14970^{\top}$ and type strains of four closely related Ochrobactrum species

Strains: 1, [O. anthropi] CCUG 50899; 2, O. rhizosphaerae PR17 $7^{\mathrm{T}} ; 3$, O. grignonense DSM $13338^{\mathrm{T}} ; 4$, O. pseudogrignonense CCUG $30717^{\mathrm{T}}$; 5 , O. thiophenivorans DSM $7216^{\mathrm{T}} ; 6$, O. anthropi CIP $14970^{\mathrm{T}}$. +, Positive; -, negative; $(+)$, weakly positive. All strains were positive for acid formation from D-glucose (in some cases, a weak positive result was observed). All strains were negative for acid formation from sucrose, D-mannitol, dulcitol, raffinose, maltose, D-arabitol, D-mannose, trehalose and methyl D-glucoside. All strains were positive for hydrolysis of L-alanine $p$-nitroanilide (pNA) and L-proline pNA and negative for hydrolysis of aesculin, $p$-nitrophenyl (pNP) $\beta$-D-galactopyranoside, pNP $\beta$-D-glucuronide, pNP phosphorylcholine and 2-deoxythymidine-5'-pNP phosphate. All strains were also positive for assimilation of $N$-acetyl-D-galactosamine, Larabinose, D-fructose, D-galactose, D-glucose, D-mannose, D-ribose, D-xylose, inositol, D-sorbitol, 4-aminobutyrate, fumarate, glutarate, DL-3hydroxybutyrate, DL-lactate, L-malate, oxoglutarate, L-alanine, $\beta$-alanine, L-aspartate, L-ornithine, L-proline and L-serine. All strains were negative for assimilation of $p$-arbutin, melibiose, salicin, putrescine, adipate, azelate, itaconate, mesaconate, suberate, L-phenylalanine, L-tryptophan, 3hydroxybenzoate, 4-hydroxybenzoate and phenylacetate.

\begin{tabular}{|c|c|c|c|c|c|c|}
\hline Test & 1 & 2 & 3 & 4 & 5 & 6 \\
\hline \multicolumn{7}{|l|}{ Acid production from: } \\
\hline Lactose & - & - & $(+)$ & - & - & - \\
\hline Inositol & - & - & - & - & $(+)$ & - \\
\hline Rhamnose & - & - & $(+)$ & $(+)$ & - & - \\
\hline D-Xylose & + & - & + & - & - & - \\
\hline Adonitol & - & - & - & - & - & $(+)$ \\
\hline Erythritol & $(+)$ & - & + & $(+)$ & $(+)$ & $(+)$ \\
\hline Melibiose & - & - & $(+)$ & - & - & - \\
\hline \multicolumn{7}{|l|}{ Hydrolysis of: } \\
\hline pNP $\alpha$-D-glucopyranoside, pNP $\beta$-D-glucopyranoside & $(+)$ & - & - & - & - & - \\
\hline pNP phenylphosphonate & + & + & - & $(+)$ & $(+)$ & - \\
\hline \multicolumn{7}{|l|}{ Assimilation of: } \\
\hline Cellobiose, maltose, maltitol & + & + & - & - & - & + \\
\hline Sucrose, trehalose, adonitol & + & + & - & + & - & + \\
\hline Acetate, propionate, pyruvate & - & + & + & + & + & + \\
\hline L-Rhamnose, cis-aconitate, citrate, L-histidine, L-leucine & + & + & + & + & - & + \\
\hline trans-Aconitate & + & + & - & + & - & - \\
\hline$N$-Acetyl-D-glucosamine & + & $(+)$ & - & - & $(+)$ & $(+)$ \\
\hline D-Gluconate & - & - & + & + & + & + \\
\hline
\end{tabular}

lipids are phosphatidylethanolamine, phosphatidylmonomethylethanolamine, phosphatidylglycerol, phosphatidylcholine and diphosphatidylglycerol. Moderate amounts of two unidentified aminolipids (AL1, AL2) and a phospholipid (PL1) and traces of several unknown phospholipids, aminolipids and lipids that have not been characterized further are also present. The fatty acid profile contains mainly $\mathrm{C}_{19: 0}$ cyclo $\omega 8 c$ and $\mathrm{C}_{18: 1} \omega 7 c$ and the hydroxy acids $\mathrm{C}_{18: 1} 2-$ $\mathrm{OH}$ and $\mathrm{C}_{18: 1}$ 3-OH. Carbon source assimilation and hydrolysis of chromogenic substrates are listed in Table 3.

The type strain CCUG $50899^{\mathrm{T}}$ (=DSM 22207 ${ }^{\mathrm{T}}$ ) was isolated from an industrial environment in Sweden.

\section{Acknowledgements}

The work was supported by a Contract Research Project for the Bundeswehr Medical Service.

\section{References}

Altenburger, P., Kämpfer, P., Makristathis, A., Lubitz, W. \& Busse, H.-J. (1996). Classification of bacteria isolated from a medieval wall painting. J Biotechnol 47, 39-52.

Busse, H.-J. \& Auling, G. (1988). Polyamine pattern as a chemotaxonomic marker within the Proteobacteria. Syst Appl Microbiol 11, 1-8.

Garrity, G. M., Bell, J. A. \& Lilburn, T. (2005). Family III. Brucellaceae Breed, Murray and Smith 1957, 394 ${ }^{\mathrm{AL}}$. In Bergey's Manual of Systematic Bacteriology, 2nd edn, vol. 2, part C, p. 370. Edited by D. J. Brenner, N. R. Krieg, J. T. Staley \& G. M. Garrity. New York: Springer.

Hall, T. A. (1999). BioEdit: a user-friendly biological sequence alignment editor and analysis program for Windows 95/98/NT. Nucleic Acids Symp Ser 41, 95-98.

Holmes, B., Popoff, M., Kiredjian, M. \& Kersters, K. (1988). Ochrobactrum anthropi gen. nov., sp. nov. from human clinical specimens and previously known as group Vd. Int J Syst Bacteriol 38, 406-416. 
Kämpfer, P. \& Kroppenstedt, R. M. (1996). Numerical analysis of fatty acid patterns of coryneform bacteria and related taxa. Can J Microbiol 42, 989-1005.

Kämpfer, P., Steiof, M. \& Dott, W. (1991). Microbiological characterization of a fuel-oil contaminated site including numerical identification of heterotrophic water and soil bacteria. Microb Ecol 21, 227-251.

Kämpfer, P., Buczolits, S., Albrecht, A., Busse, H.-J. \& Stackebrandt, E. (2003). Towards a standardized format for the description of a novel species (of an established genus): Ochrobactrum gallinifaecis sp. nov. Int J Syst Evol Microbiol 53, 893-896.

Kämpfer, P., Scholz, H. C., Huber, B., Falsen, E. \& Busse, H.-J. (2007). Ochrobactrum haematophilum sp. nov. and Ochrobactrum pseudogrignonense sp. nov., isolated from human clinical specimens. Int J Syst Evol Microbiol 57, 2513-2518.

Kämpfer, P., Sessitsch, A., Schloter, M., Huber, B., Busse, H.-J. \& Scholz, H. C. (2008). Ochrobactrum rhizosphaerae sp. nov. and Ochrobactrum thiophenivorans sp. nov., isolated from the environment. Int J Syst Evol Microbiol 58, 1426-1431.

Lebuhn, M., Achouak, W., Schloter, M., Berge, O., Meier, H., Barakat, M., Hartmann, A. \& Heulin, T. (2000). Taxonomic characterization of Ochrobactrum sp. isolates from soil samples and wheat roots, and description of Ochrobactrum tritici sp. nov. and Ochrobactrum grignonense sp. nov. Int J Syst Evol Microbiol 50, 2207-2223.

Pitcher, D. G., Saunders, N. A. \& Owen, R. J. (1989). Rapid extraction of bacterial genomic DNA with guanidium thiocyanate. Lett Appl Microbiol 8, 151-156.

Richards, G. M. (1974). Modification of the diphenylamine reaction giving increased sensitivity and simplicity in the estimation of DNA. Anal Biochem 57, 369-376.

Scholz, H. C., Tomaso, H., Al Dahouk, S., Witte, A., Schloter, M., Kämpfer, P., Falsen, E. \& Neubauer, H. (2006). Genotyping of Ochrobactrum anthropi by recA-based comparative sequence, PCRRFLP, and 16S rRNA gene analysis. FEMS Microbiol Lett 257, 7-16.

Scholz, H. C., Al Dahouk, S., Tomaso, H., Neubauer, H., Witte, A., Schloter, M., Kämpfer, P., Falsen, E., Pfeffer, M. \& Engel, M. (2008). Genetic diversity and phylogenetic relationships of bacteria belonging to the Ochrobactrum-Brucella group by recA and 16S rRNA genebased comparative sequence analysis. Syst Appl Microbiol 31, 1-16.

Stolz, A., Busse, H.-J. \& Kämpfer, P. (2007). Pseudomonas knackmussii sp. nov. Int J Syst Evol Microbiol 57, 572-576.
Tamura, K., Dudley, J., Nei, M. \& Kumar, S. (2007). MEGA4: molecular evolutionary genetics analysis (MEGA) software version 4.0. Mol Biol Evol 24, 1596-1599.

Teyssier, C., Marchandin, H., Siméon De Buochberg, M., Ramuz, M. \& Jumas-Bilak, E. (2003). Atypical 16S rRNA gene copies in Ochrobactrum intermedium strains reveal a large genomic rearrangement by recombination between rrn copies. J Bacteriol 185, 29012909.

Teyssier, C., Marchandin, H., Jean-Pierre, H., Masnou, A., Dusart, G. \& Jumas-Bilak, E. (2007). Ochrobactrum pseudintermedium sp. nov., a novel member of the family Brucellaceae, isolated from human clinical samples. Int J Syst Evol Microbiol 57, 1007-1013.

Thompson, J. D., Gibson, T. J., Plewniak, F., Jeanmougin, F. \& Higgins, D. G. (1997). The CLUSTAL_X windows interface: flexible strategies for multiple sequence alignment aided by quality analysis tools. Nucleic Acids Res 25, 4876-4882.

Tindall, B. J. (1990a). A comparative study of the lipid composition of Halobacterium saccharovorum from various sources. Syst Appl Microbiol 13, 128-130.

Tindall, B. J. (1990b). Lipid composition of Halobacterium lacusprofundi. FEMS Microbiol Lett 66, 199-202.

Tripathi, A. K., Verma, S. C., Chowdhury, S. P., Lebuhn, M., Gattinger, A. \& Schloter, M. (2006). Ochrobactrum oryzae sp. nov., an endophytic bacterial species isolated from deep-water rice in India. Int J Syst Evol Microbiol 56, 1677-1680.

Trujillo, M. E., Willems, A., Abril, A., Planchuelo, A. M., Rivas, R., Ludeña, D., Mateos, P. F., Martínez-Molina, E. \& Velázquez, E. (2005). Nodulation of Lupinus by strains of the new species Ochrobactrum lupini sp. nov. Appl Environ Microbiol 71, 1318-1327.

Velasco, J., Romero, C., López-Goñi, I., Leiva, J., Díaz, R. \& Moriyón, I. (1998). Evaluation of the relatedness of Brucella spp. and Ochrobactrum anthropi and description of Ochrobactrum intermedium sp. nov., a new species with a closer relationship to Brucella spp. Int $J$ Syst Bacteriol 48, 759-768.

Ziemke, F., Höfle, M. G., Lalucat, J. \& Rosselló-Mora, R. (1998). Reclassification of Shewanella putrefaciens Owen's genomic group II as Shewanella baltica sp. nov. Int J Syst Bacteriol 48, 179-186.

Zurdo-Piñeiro, J. L., Rivas, R., Trujillo, M. E., Vizcaino, N., Carrasco, J. A., Chamber, M., Palomares, A., Mateos, P. F., Martínez-Molina, E. \& Velázquez, E. (2007). Ochrobactrum cytisi sp. nov. isolated from nodules of Cytisus scoparius in Spain. Int J Syst Evol Microbiol 57, 784788. 